\title{
Quantitative determination of residual 2-(2-chloroethoxy) ethanol (CEE) in quetiapine fumarate by gas chromatogaraphy
}

\author{
Pravish Tiwari, Ravi Yadav, Padmakar Sathe, Deepali Gangrade
}

Department of chemistry, Ramnarain Ruia College, Matunga, Mumbai, India.

Email: pravishkumar1981@yahoo.com

Received 6 July 2010; revised 19 July 2010; accepted 26 July 2010.

\begin{abstract}
A simple and specific gas chromatographic method developed and validated for the determination of 2-(2-chloroethoxy) ethanol in Quetiapine Fumarate. The method is carried out with a flame ionization detector and DB-FFAP capillary column. The linearity was established over a range of $40-150 \mu \mathrm{gll}^{-1}$ and correlation coefficient is more than 0.999 .
\end{abstract}

Keywords: GC; 2-(2-Chloroethoxy) Ethanol

\section{INTRODUCTION}

Quetiapine is an antipsychotic drug belonging to the group of the dibenzothiazepines and used for the treatment of schizophrenia and other psychotic syndromes $[1,2]$. Quetiapine is used in a form of tablets containing $50,100,200$ and $300 \mathrm{mg}$ of the active substance.The starting material which is used in the synthesis of Quetiapine fumarate is 2-(2-chloroethoxy) ethanol. 2-(2-chloroethoxy)-ethanol: CEE, structural formula C4H9ClO2; CAS number 628-89-7, boiling point $200^{\circ} \mathrm{C}$ at $101.3 \mathrm{kPa}$. The starting material are often not totally removed by practical manufacturing techniques, and consequently low levels are present in most pharmaceuticals. An acceptable level of CEE is unclassified but it is known impurity so was specified with acceptance criterion of $0.01 \%$ [3]. \{Based on NOEL and PDE Value of CEE and Quetiapine The European Pharmacopoeia (Eur. $\mathrm{Ph}$.) included this guideline in the chapter Residual Solvents $[4,5]$ and described a general procedure for identification and control of residual solvents in drug substances. Some problems have been overcome, for instance quantitative determination of non-volatile solvents such as 2-(2-chloroethoxy)-ethanol (CEE). In the literature there is no information about the methods for determination of CEE in the Quetiapine. In the present study, a gas chromatographic method with direct injection for the determination of CEE in the active substance has been developed.

The separation was obtained on a DB-FFAP column ( $30 \mathrm{~m} \times 0.32 \mathrm{~mm}$ i.d. $\times 1.0 \mu \mathrm{m}$ coating thickness).

\section{EXPERIMENTAL}

The active substance was synthesized by Precise pharmaceutical Ltd (Pharmaceutical Research Centre, Mumbai, India). Acetonitrile was purchased by J.T baker (USA), Hydrochloride was purchased by S.D. Fine chem. (India), Water was purchased by Lab chem. (India), and 2-(2-chloroethoxy) ethanol was purchased by Sigma Aldrich, (Germany).

\subsection{Preparation of Solution}

Quantitative standard solution of CEE Standard solutions was prepared from standard stock solutions. Standard stock solutions were prepared in Diluent $\{0.2 \mathrm{~N}$ Hydrochloride in Acetonitrile: Water (70:30 v/v)\}. Standard stock solution A: containing $1 \mathrm{mg} \mathrm{ml}^{-1}$ of CEE; Standard solution: containing $0.01 \mathrm{mg} \mathrm{ml}^{-1}$ of CEE which corresponds to $0.1 \mathrm{mg} \mathrm{ml}^{-1}$ of CEE in the tested substance. Qualitative standard solution of CEE for system suitability: Selectivity solution was prepared to check Eur. Ph. system suitability requirements. A total of 7 solvents were included in this standard solution. Selectivity solution contained $300 \mathrm{ppm}$ of methanol, 500ppm of Ethanol, 500ppm of Acetone, 500 ppm of Isopropyl alcohol, $89 \mathrm{ppm}$ of Toluene, $88 \mathrm{ppm}$ of N, N-dimethyl formamide, $60 \mathrm{ppm}$ of Dichloromethane and $10 \mathrm{ppm}$ of CEE [6]. Test solution was prepared solution 1 containing $100 \mathrm{mg} \mathrm{ml}^{-1}$. A blank was prepared using the diluent, but without sample or standard solution.

\subsection{Instrumentation and Operating Condition}

The experiments were performed on an Agilent 7890A gas chromatograph (GC) equipped with a CTC combipal autosampler and a flame ionization detector. A DB-FFAP column (phase composition: Nitroterepthalic acid modi- 
fied polyethylene Glycol) film thickness $1.0 \mu \mathrm{m}, 30 \mathrm{~m}$ long, $0.32 \mathrm{~mm}$ ID was used. GC conditions: Inlet heater $200^{\circ} \mathrm{C}$, detector $280^{\circ} \mathrm{C}$, Oven initial temperature $100^{\circ} \mathrm{C}$ for 5 minutes, then raised at a rate of $15^{\circ} \mathrm{C} / \mathrm{min}$ to $180^{\circ} \mathrm{C}$ and hold for 2 minutes, then raised at a rate of $35^{\circ} \mathrm{C} / \mathrm{min}$ to $230^{\circ} \mathrm{C}$ and hold for 2 minutes. Helium gas was used as

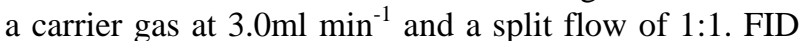
air flow was $400 \mathrm{ml} \mathrm{min}^{-1}$ and FID hydrogen flow was $40 \mathrm{ml} \mathrm{min}^{-1} .1 \mu \mathrm{l}$ was injected.

\subsection{Procedure}

Separately inject $1 \mu \mathrm{l}$ of standard solution and test solution into gas chromatograph. Record chromatograms and compare peak areas of analytes from the test and standard solution. Under described conditions the retention time of CEE is 10.7 minutes. The area of the peak of CEE in the chromatogram from the test solution must not be greater than the mean area of the peak from the standard solution $\left(0.1 \mathrm{mg} \mathrm{ml}^{-1}\right.$ corresponds to the substance).

\section{RESULTS}

\subsection{System Suitability Test (SST)}

The selectivity of the method was evaluated by injecting the selectivity solution to ensure the separation of all

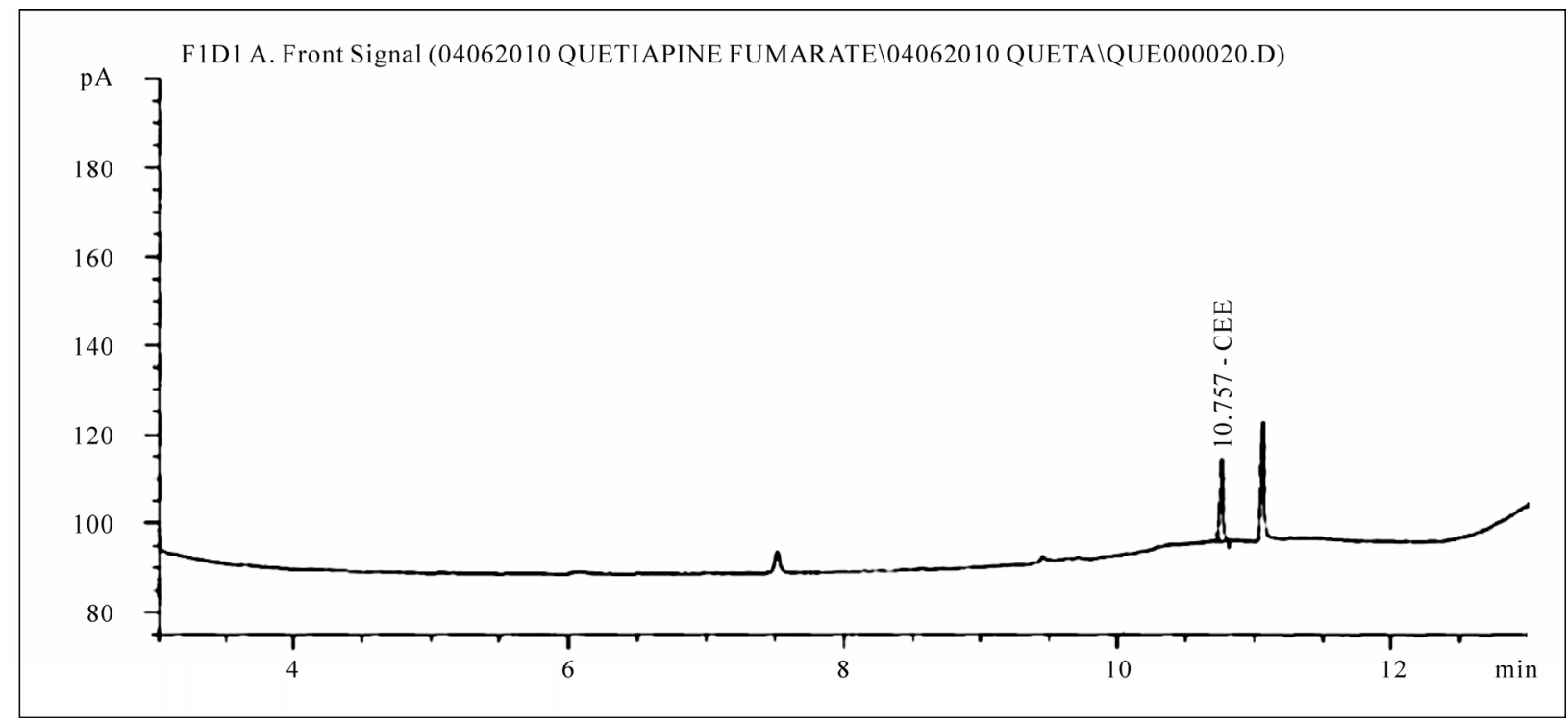

Figure 1. Standard chromatogram of CEE.

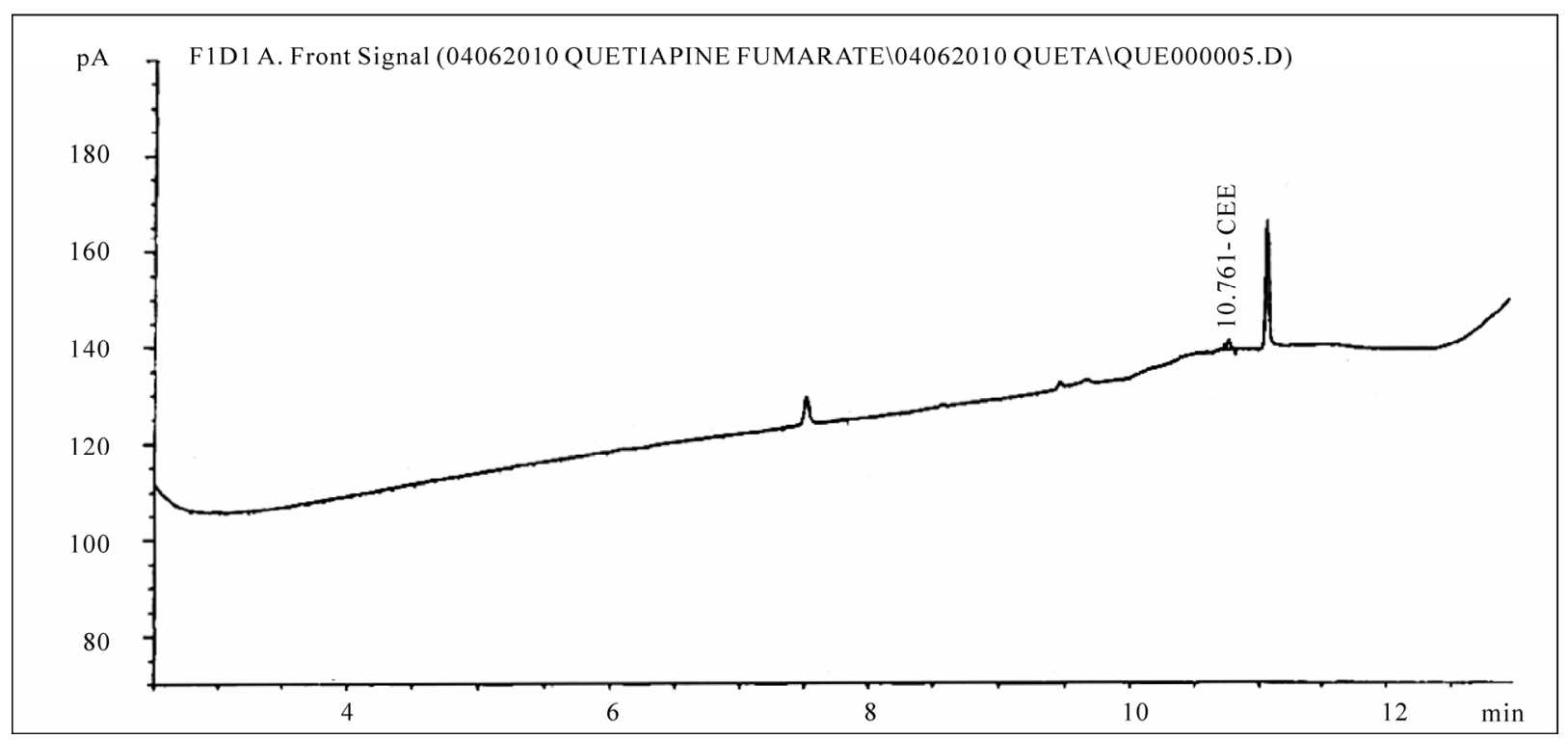

Figure 2. Limit of Detection of CEE. 
analytes. The selectivity solution contained: Methanol, Ethanol, Acetone, Dichloromethane, toluene, Isopropyl alcohol, N, N-Dimethyl formamide, CEE. Resolution was calculated directly by the software: Chemstation solution ver. Rev.13.03.02 [341]. Chromatogram of selectivity solution is shown in Figure 1; the results are presented in Figure 1 (inset).Good separation was obtained between CEE and other solvents used in the synthetic route of the active substance. For the drug substance excellent recoveries of 92-95\% were obtained at
$0.1 \mathrm{mg} \mathrm{ml}^{-1}$ corresponds to the substance.

\subsection{Validation of Method for CEE in API}

Full validation data was required for API as it was in last stage development.

\subsection{Limit of detection and limit of Quantification for CEE}

The LOD and LOQ were calculated form S/N data generated from six injection of CEE (with API) containing

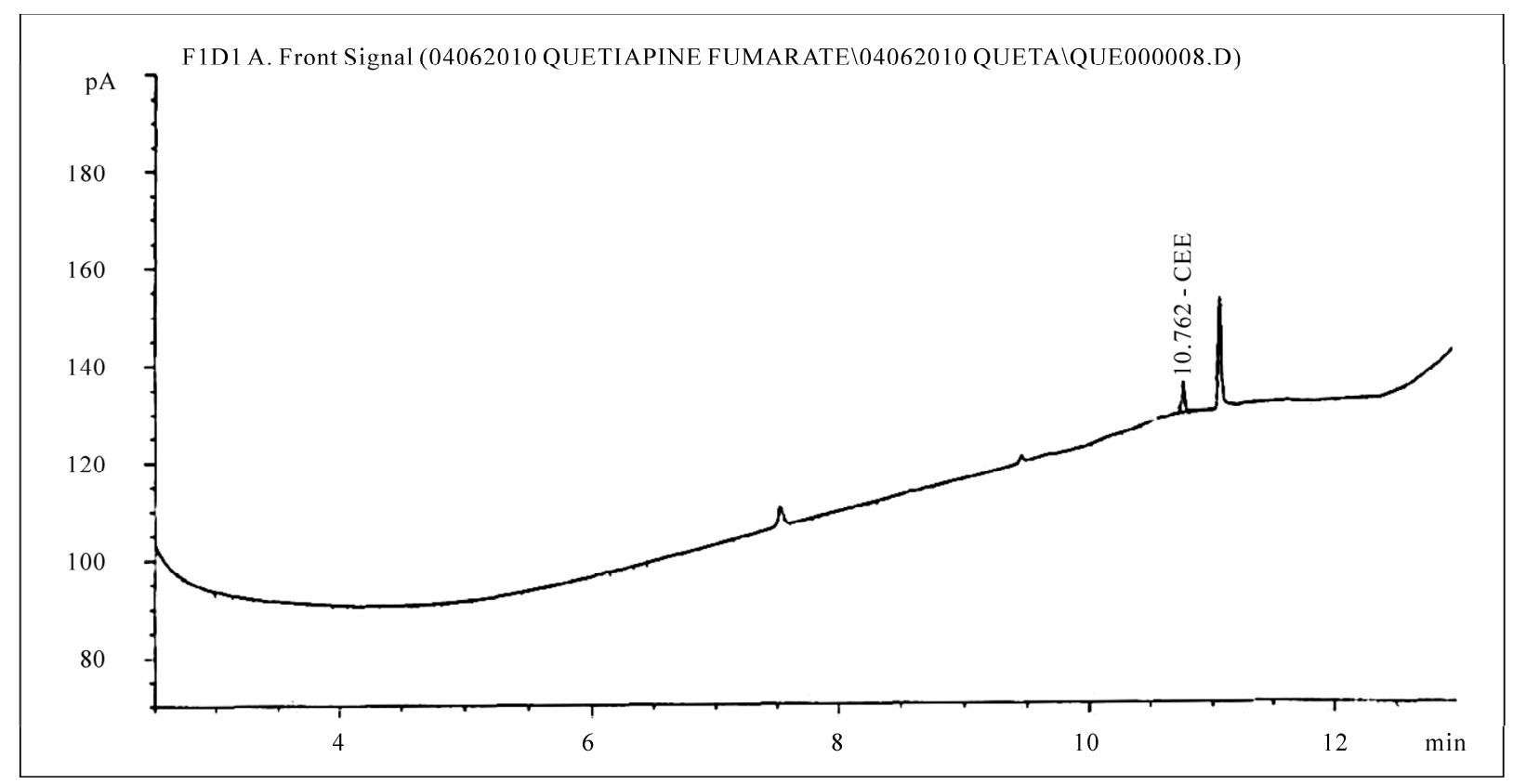

Figure 3. Limit of Quantification of CEE.

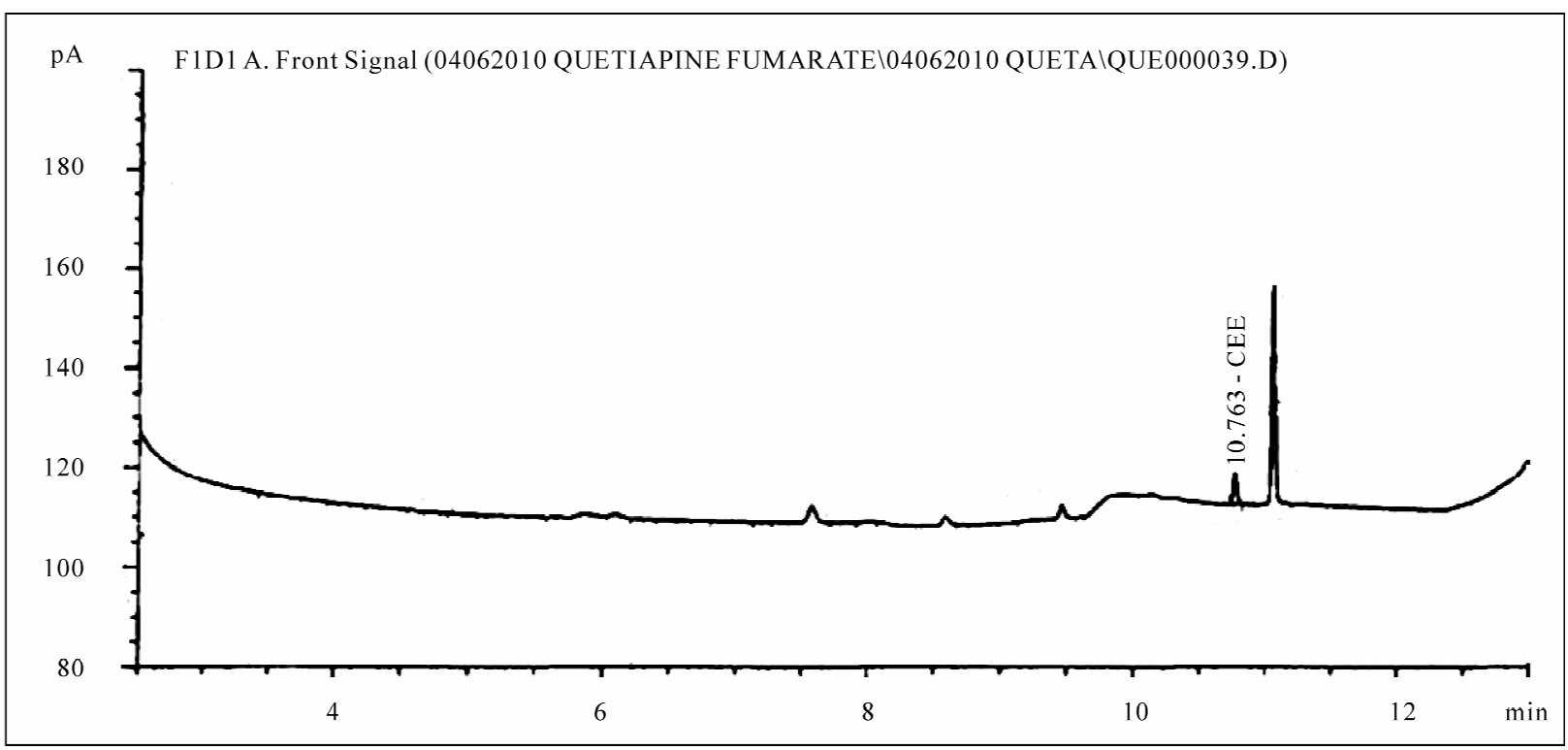

Figure 4. Accuracy at Limit of quantification level. 
$0.1 \mathrm{mg} \mathrm{ml}^{-1}$ with respect to an API sample concentration $100 \mathrm{mg} \mathrm{ml}^{-1}$. A LOQ of $0.04 \mathrm{mg} \mathrm{ml}^{-1}$ is typical for the CEE with a LOD approximately three times less than LOQ. LOD and LOQ chromatograms are shown in the Figures 2 \& 3.

\subsection{Recovery of CEE in API}

The accuracy of the method was evaluated in triplicate at LOQ level in bulk drug sample. The percentage recoveries were calculated. A satisfactory recovery value of CEE (90-92\%) was obtained. At such low levels these recoveries and \%RSD were satisfactory. Accuracy at LOQ and STD chromatogram was shown in Figures 4 \&
5.

\subsection{Linearity of the CEE on Gas Chromatography}

The linearity of CEE was satisfactorily demonstrated with six point calibration graph between LOQ to $150 \%$ of analyte concentrations (LOQ, 50, 75,100,125 \& 150). The peak area versus concentration data was performed by least-squares linear regression analysis. The calibration curve was produced by plotting the average of triplicate CEE injections against the concentration expressed in percentage. Correlation coefficient for CEE was 0.99. Linearity of the CEE chromatogram was shown in the

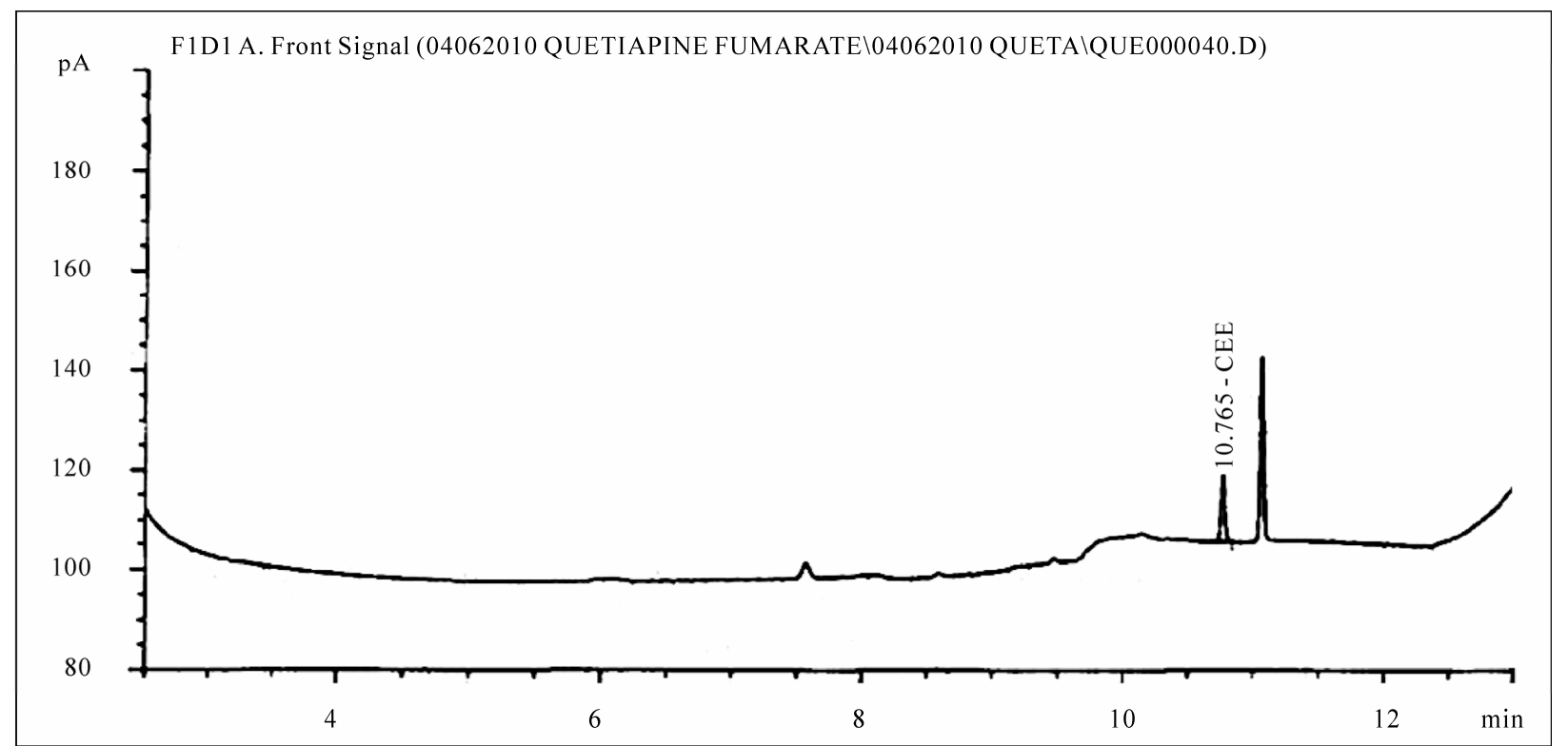

Figure 5. Accuracy at Standard level.

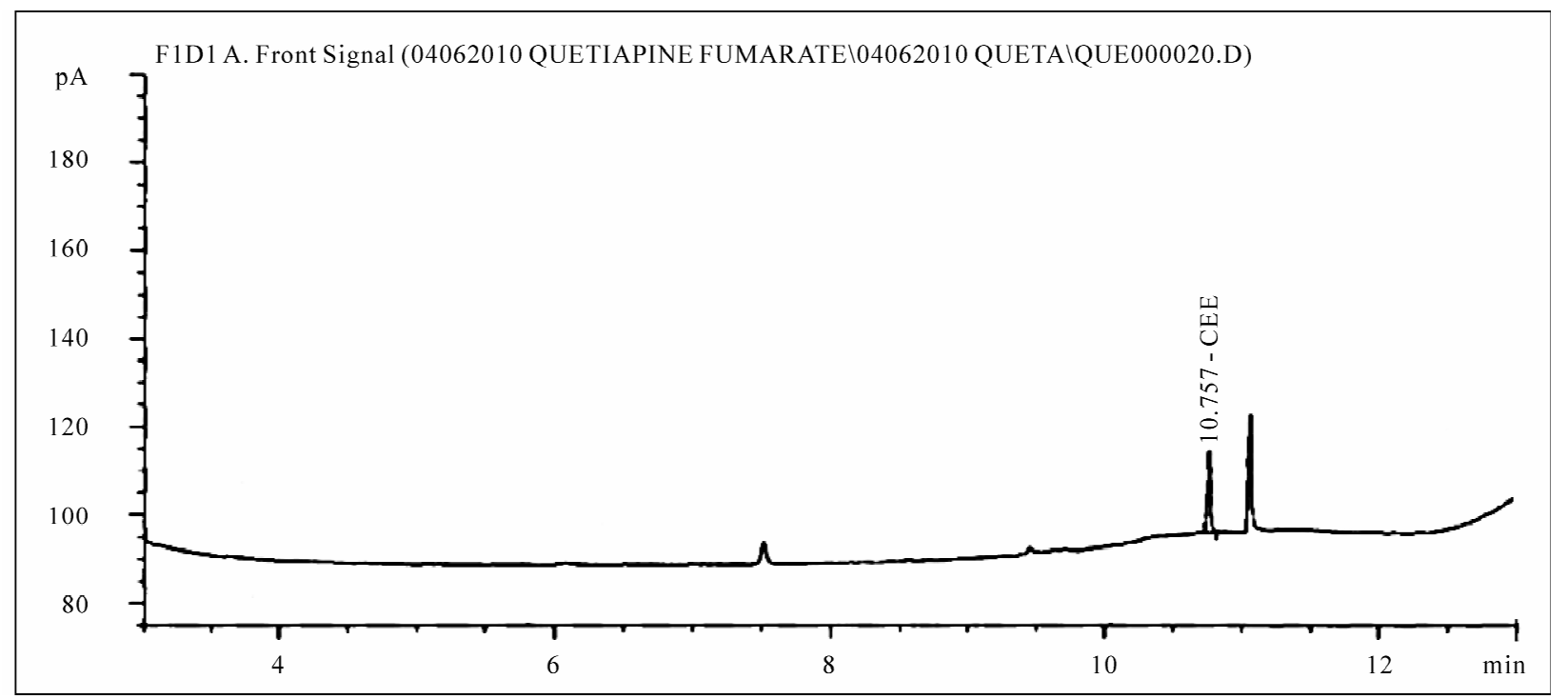

Figure 6. Linearity at standard level CEE. 
Figure 6.

\section{DISCUSSION AND CONCLUSION}

In this study, a GC analytical method was developed for control of residual 2-(2-chloroethoxy)ethanol (CEE) in the active substance. Sample solvent diluent was selected to obtain good selectivity and sensitivity for CEE. The sample dilution factor was adapted to detect unclassified solvent CEE at known impurity levels (100 ppm) by FID. This GC method is suitable for its intended purpose.

\section{REFERENCES}

[1] Richelson, E. (1999) J. Clin. Psychiatry, 60(Suppl 10), 5.

[2] Caley, C.F. and Rosenbaum, S. (1998) Formulary, 33, 105.
[3] Proceedings of International Conference on Harmonisation of Technical Requirements for Registration of Pharmaceuticals for Human Use (ICH), Tripartite harmonised guideline Q3A (R) Impurities in new drug substancesî, 2002.

[4] The European Agency for the Evaluation of Medicinal Products Evaluation of Medicines for Human Use, ICH Topic Q3C (M) Maintenance of Note for guidance on Impurities: Residual solvents (CPMP/ICH/283/95), Permissible Daily Exposure (PDE) for Tetrahydrofuran and N-Methylpyrrolidoneî.

[5] Residual solvents (5.4) (2004) European Pharmacopoeia, Supplement 4.6., Directorate for the Quality of Medicines of the Council of Europe, Strasbourg, 4th Edition, 3911.

[6] Proceedings of International Conference on Harmonization of Technical Requirements for Registration of Pharmaceuticals for Human Use (ICH), Tripartite harmonised guideline Q3C Impurities: Residual Solvent’s, 1997. 